\title{
Abruptio placenta: a retrospective study on maternal and perinatal outcome
}

\section{Subha Sivagami Sengodan*, Mohana Dhanapal}

Department of Obstetrics and Gynecology, Government Mohankumarmangalam Medical College Salem, Tamil Nadu, India

Received: 10 July 2017

Revised: 05 September 2017

Accepted: 09 September 2017

\section{*Correspondence:}

Dr. Subha Sivagami Sengodan,

E-mail: drppsamysubha@gmail.com

Copyright: () the author(s), publisher and licensee Medip Academy. This is an open-access article distributed under the terms of the Creative Commons Attribution Non-Commercial License, which permits unrestricted non-commercial use, distribution, and reproduction in any medium, provided the original work is properly cited.

\section{ABSTRACT}

Background: Abruptio placenta is separation of a normally situated placenta after 20 weeks of gestation and prior to the birth of the fetus. It is an important cause of antepartum haemorrhage and presents as an acute abdomen in the third trimester of pregnancy. Obstetrical haemorrhage is one of the triad (Haemorrhage hypertension and infection) of causes of maternal deaths in both developed and underdeveloped countries.

Methods: This is a retrospective study of Abruptio Placenta cases carried out between January 2015 and December 2015 at Government Mohan Kumaramangalam Medical College Hospital, Salem and about its perinatal and maternal outcome.

Results: Incidence of Abruptio placenta is $0.5 \%$. It is most common in the women of age group 26-30yrs. 67\% of cases were associated with severe pre-eclampsia. Live births were $69.8 \%$ while stillbirths were $30.2 \%$. PPH occurred in $19.6 \%$ of cases. DIC accounts for $16.7 \%$ of the complication.

Conclusions: Abruptio placenta is associated with poor maternal and fetal outcome. Hence early diagnosis and prompt resuscitative measures would prevent both perinatal and maternal mortality and morbidity.

Keywords: Abruptio Placenta, Maternal Outcome, Perinatal Outcome

\section{INTRODUCTION}

Placental abruption is the most common cause of antepartum haemorrhage and is defined as premature separation of normally implanted placenta. ${ }^{1}$ The detached portion of placenta is unable to exchange gases and nutrients when the remaining fetoplacental unit is unable to compensate for this loss of function, the fetus is compromised. The incidence appears to be increasing probably due to increase in prevalence of the risk factors for the disorder. Placental abruption is due to rupture of uterine spiral artery. Bleeding into deciduas leads to separation of placenta. Hematoma formation further separates the placenta from the uterine wall causing compromise of the blood supply to the fetus. The types
are-A-Revealed-blood tracks between the membranes and escapes through the vagina and cervix. B-blood collects behind the placenta with no evidence of vaginal bleeding. It is a serious obstetric condition that increases maternal and neonatal morbidity and mortality. ${ }^{2}$ Abruption occurs in $0.4-1 \%$ of pregnancies. Obstetric haemorrhage accounts for $1 / 3^{\text {rd }}$ of maternal death. Perinatal mortality is high with abruption due to its strong association with preterm. Even babies born at 40weeks of gestation, birth weight of $3.5-3.9 \mathrm{~kg}$ had 25 -fold higher mortality with abruption. ${ }^{3}$ Primary cause of abruption is not known but the main precipitating and predisposing factors of abruption are age, parity, anemia, poor nutrition, pregnancy induced hypertension, eclampsia, gestational diabetes mellitus, premature rupture of membrane, and 
previous medical termination of pregnancy. ${ }^{4}$ Abruption is a significant cause of maternal and perinatal morbidity and mortality. Placental abruption may be total or partial, causing pain and vaginal bleeding-which are the hallmarks of placental abruption. Abruptio placenta is the major cause of haemorrhagic shock, DIC, renal failure, ischemic necrosis of organs in the mother. Fetal complications include hypoxia, anemia, growth restriction, prematurity, neurodevelopmental problems and premature death. Hypertensive disorder of pregnancy is associated with $2.5 \%$ to $17.9 \%$ of placental separation. ${ }^{5}$ Maternal and fetal survival depends on early diagnosis and intervention.

\section{METHODS}

This is a retrospective study by analysing the case sheets of abruptio placenta in Government Mohan Kumaramangalam Medical College Hospital, Salem from January 2015 to December 2015. From those case records, details regarding the age of the patient, parity and maternal high-risk factors were collected. All other causes of APH like placenta previa and other extraplacental causes were excluded. All study patients underwent a complete obstetrical examination and clinical workup including history, general physical examination and abdominal and pelvic examination. Detailed obstetric history was obtained and maternal high- risk factors like PIH, GDM, polyhydramnios was noted. As $95 \%$ patients were admitted as emergencies, placental abruption was suspected depending on clinical features of vaginal bleeding, uterine tenderness, hypertonic uterus and diagnosis was confirmed by retroplacental clots. After initial resuscitation mode of delivery was decided depending upon state of mother and fetus. Relevant investigations such as lab tests and imaging were performed. Socioeconomic status of the patient was calculated as per modified kuppusamy's scale. Fetal well-being was assessed with ultrasonography and cardiotocography. Diagnosis was confirmed by the presence of retroplacental clots which was used to estimate the amount of bleeding and severity of abruption. Patients were managed according to the fetal and maternal conditions. All information's were gathered and results were analysed. Maternal complications studied were PPH, DIC, ARF, shock, pulmonary edema and infections. Fetal outcome in the form of perinatal mortality (still births and neonatal deaths), prematurity and admission to the neonatal care unit were studied.

\section{RESULTS}

Total number of deliveries from January 2015-December 2015 were 6917. Total number of abruptio placenta cases from January 2015- December 2015 were 40. The results of the present study showed increased incidence of severe preeclampsia with abruption. Increasing age has been implicated as a predisposing factor in Abruptio placenta. Mean age of patients of APH was 26-30 years. Most of the patients were unbooked and not taking antenatal care. Incidence was high in multiparous women.

Mainly abruption was seen in term pregnancy. Most of them were associated with anemia and PIH, and the mode of delivery varied accordingly. Major complication on maternal side were shock.

Table 1: Age.

\begin{tabular}{|l|l|}
\hline Age & $\%$ \\
\hline$<20$ years & 9.3 \\
\hline $20-25$ years & 34.7 \\
\hline $26-30$ years & 40.6 \\
\hline$>30$ years & 15.4 \\
\hline
\end{tabular}

Most of the abruptio placenta cases were between 26 to 30 years $40.6 \%$. Next most common age group were between 20 to 25 years. Least incidence was seen among the age group <20yrs.

Table 2: Parity.

\begin{tabular}{|ll|}
\hline Parity & $\%$ \\
\hline Primi & 22 \\
\hline G2 & 42.4 \\
\hline G3 & 26 \\
\hline G4, G5 & 9.6 \\
\hline
\end{tabular}

Maximun number of abruptio placenta cases were $2^{\text {nd }}$ Gravida. Incidence of abruption was high in multiparous women and mainly abruption was seen in term pregnancy.

Table 3: Association with PIH.

\begin{tabular}{|ll|}
\hline Type & $\%$ \\
\hline Severe Pre-eclampsia & 67 \\
\hline Eclampsia & 8.6 \\
\hline Chronic-HT & 7 \\
\hline Normal BP & 17.4 \\
\hline
\end{tabular}

Abruption was more common among patients who had severe preeclampsia than who were normotensive. Most of them were associated with anemia and PIH. Even normotensive groups had Abruption which was about $17.4 \%$.

Table 4: Fetal outcome.

\begin{tabular}{|c|c|}
\hline Fetal outcome & $\%$ \\
\hline Still birth & 30.2 \\
\hline Live birth & 69.8 \\
\hline
\end{tabular}

$69.8 \%$ had live birth. $30.2 \%$ had still born. Among them 5 died in early neonatal period due to prematurity. Fetal complications included hypoxia, anemia, growth restriction, prematurity, neurodevelopmental problems, prematurity and fetal death. 
Table 5: Maternal complications.

\begin{tabular}{|ll|}
\hline Complications & $\%$ \\
\hline PPH & 19.6 \\
\hline DIC & 16.7 \\
\hline ARF & 11.3 \\
\hline Shock & 10.5 \\
\hline Pulmonary edema & 10.2 \\
\hline Infections & 9.8 \\
\hline Others & 21.9 \\
\hline
\end{tabular}

Maternal complications associated with Abruption were Postpartum haemorrhage (PPH), Disseminated Intravascular Coagulation (DIC), Acute renal failure (ARF), Shock, Pulmonary edema, Infection. Among which Postpartum hemorrhage contributes the majority of complications (19.6\%).

\section{DISCUSSION}

Placental abruption is one of the serious complications of pregnancy, as it leads to both poor maternal and fetal outcome. The incidence of abruptio placenta was $0.5 \%$ in our study, which is similar to study by Wasnik SK. ${ }^{7}$ The signs and symptoms of abruptio placenta vary depending upon the severity of bleeding and the degree of separation of the placenta. Abruption can occur at any stage in pregnancy but 32-36 weeks appears to be the most vulnerable period 8 . We found $67 \%$ of patients with severe preeclampsia, $8.6 \%$ of patients with eclampsia, $7 \%$ of patients with chronic hypertension developed abruption in our study. Among the maternal complications, Postpartum Hemorrhage( $\mathrm{PPH})$ was commonest followed by Disseminated Intravascular coagulation (DIC), Acute Renal Failure (ARF), shock, pulmonary edema and infection. PPH occurred in 19.6\% of patients in our study, were as study by Talpur NN reported PPH in $28 \%$ of patients. ${ }^{9}$ DIC was associated with $16.7 \%$ of the patients in our study. Sher G observed DIC in $10-20 \%$ of his study patients with severe abruption and fetal demise which is comparable to our study. ${ }^{10}$ Renal failure is one of the major causes of maternal death. ${ }^{11}$ We found ARF is reported in $11.3 \%$ of the cases and Shock in $10.5 \%$ were as study from Shrivatsava V reported $24.6 \%$ shock cases. ${ }^{12}$ Pulmonary edema occurred in $10.2 \%$ of patients in our study which is comparable to study by Subramaniyan V were it is reported in $9.3 \%$ of the cases. ${ }^{13}$ Puerperal sepsis was found to be in $17.5 \%$ of patients in the study by Choudhary V, in our study it is reported in $9.8 \%$ of the patients. ${ }^{14}$ Regarding fetal outcome, $69.8 \%$ were born alive and $30.2 \%$ were still births. Abruption was not an independent risk factor for poor outcome among infants born before 32 weeks of gestation. A premature delivery can increase the fetal morbidity in cases of abruption. ${ }^{15-19}$ Routine antenatal check-up, correction of anemia, timely referral, timely caesarean section, liberal blood and blood components transfusion and good neonatal intensive care unit will help further to lower the perinatal and maternal morbidity and mortality.

\section{CONCLUSION}

This study reveals that Severe pre-eclampsia, eclampsia, chronic hypertension, high parity are independent risk factors for abruptio placenta. Antenatal care which identifies the risk factors like PIH plays an important role in decreasing the incidence of abruptio placenta and improving the maternal and fetal outcome. Regular antenatal checkup, anemia correction, early diagnosis \& identification of gestational hypertension would prevent the maternal and perinatal morbidity and mortality. It should be managed in centers where advanced maternal and neonatal facilities are available. Though maternal morbidity is reduced with modern management of abruptio placenta, timely diagnosis and intervention is necessary. Early detection and active management will reduce morbidity. Team efforts by obstetricians, intensivists and neonatologist is required for better maternal and fetal outcome.

\section{Funding: No funding sources \\ Conflict of interest: None declared \\ Ethical approval: Not required}

\section{REFERENCES}

1. Konje JC, Taylor DJ. Bleeding in later pregnancy. In: James DK, Steer PJ, Weiner CP, Gonik B editors. High risk pregnancy $3^{\text {rd }}$ ed. Philadelphia: Pennsylvania; 2006. 1266-71.

2. Pitaphrom A, Sukcharoen N. Pregnancy outcomes in placental abruption. J Med Oncolassoc Thai. 2006; $1572-8$.

3. Ananth CV, Lavery JA, Vintzileos AM. Severe Placental Abruption:Clinical definition and associations with maternal complications. Am J Obstet Gynaecol. 2016;214;272.e1-9

4. Kyrklund-Bloomberg BN, Gennser G, Cnattinguis S. Placental abruption and perinatal death. Paediatr Perinat Epidemiol. 2001;15:290-7.

5. Willium A, Lieberman E, Mittendorf R. Risk factors of abruption placentae. A J of Epidemiol. 1991; 134(9):965-72.

6. Menom MK, Sokshi SK. Accidental haemorrhage in teaching hospital. J Obstet Gynaecol Ind. 1961; 11:335-41.

7. Wasnik SN and Naiknaware SV. Antepartum Haemorrhage: Causes and its effects on Mother Child: An Evaluation. Obstetri Gynaecol Internat J. 2015;3(1):00072.

8. Bibi S, Ghaffer S, Pir MA, Yousfani S. Risk factors and clinical outcome in placental abruption: a retrospective analysis J Pak Medic Associat. 2009:59(10):672-4.

9. Talpur NN, Memon SR, Jamro B, Korejo R. Maternal and fetal morbidity with abruptio placentae. Rawal Med J. 2011;36(4):297-300.

10. Sher G. Pathogenesis and management of uterine inertia complicating abruptio placentae with 
consumption coagulopathy. Am J Obstet Gynecol. 1977;129:164-70.

11. Campbell S, Lee C. Disorders of placentation. In: Obstetrics by ten teacher $17^{\text {th }}$ ed. Arnold London 2002.p.171-3.

12. Shrivastava V, Kotur $P$, Jauhari A. Maternal and Fetal outcome among Abruptio Placentae at a rural tertiary hospital in Karnataka, India: A Retrospective analysis. Int J Res Med Sci. 2014;2(4):1655-8.

13. Subramaniyan V, Pachamuthu U, Dhanapal M, Abruptio Placentae: A Retrospective Study. 2016;5:10.

14. Choudhary V. Rathi Somani S, Somani S. Evaluation of Risk factors and Obstetric and Perinatal Outcome in Abruptio Placentae. 2015;14(5):36-9.

15. Humayun S, Nahid F. Comparison of pregnancy outcome among placenta praevia and abruption, Ann King Edward Med Coll. 2005;11(1):58-9.

16. Pitaphrom A, Sukcharoen N. Pregnancy outcome in placental abruption. J Med Assoc Thai. 2006;89(10):1572-8.
17. Sheiner E, Shoham-Vardi I, Hadar, Hallak M. Incidence, obstetric risk factors and pregnancy outcome of preterm placental abruption: a retrospective analysis. J Matern Fetal Neonatal Med. 2002;11(1):34-9.

18. Allred LS, Batton D. The effect of placental abruption on the short-term outcome of premature infants. Am J Perinatol. 2004:21(3):157-62.

19. Ananth CV, Getahun D, Peltier MR, Smulian JC. Placental abruption in term and preterm gestations: evidence for hetrogenicity in clinical pathways. Obstet Gynecol. 2006;107(4):785-92.

Cite this article as: Sengodan SS, Dhanapal M. Abruptio placenta: a retrospective study on maternal and perinatal outcome. Int J Reprod Contracept Obstet Gynecol 2017;6:4389-92. 